Dicle University Journal of Engineering (DUJE)

Araştırma Makalesi / Research Article

\title{
Transfer Matris Metodu ile Fonksiyonel Derecelendirilmiş Sandviç Kirişlerin Titreşim Analizi
}

\section{Vibration Analysis of Functionally Graded Sandwich Beams with Transfer Matrix Method}

\author{
Pınar Aydan Demirhan ${ }^{1 *}$, Vedat Taşkın²
}

${ }^{1}$ Trakya Üniversitesi, Makine Mühendisliği Bölümü, Edirne, pinard@ trakya.edu.tr

${ }^{2}$ Trakya Üniversitesi, Makine Mühendisliği Bölümü, Edirne, vedattaskin@ trakya.edu.tr

\begin{tabular}{|c|c|}
\hline MAKALE BİLGİLERİ & ÖZET \\
\hline Makale geçmişi: & \multirow{6}{*}{$\begin{array}{l}\text { Fonksiyonel derecelendirilmiş malzemeler geleneksel malzemelerin uygun olmadığı çalışma koşulları için } \\
\text { tasarlanmış özel bir kompozit malzeme sınıfidır. Malzeme özellikleri istenen doğrultuda bir fonksiyona bağl1 } \\
\text { olarak deģişmektedir. Malzeme özelliklerinde keskin geçişler olmaması nedeniyle katmanlı kompozit yapılarda } \\
\text { karşılaşılan problemleri ortadan kaldıran fonksiyonel derecelendirilmiş malzemeler sandviç yapılar içinde öz veya } \\
\text { yüzey tabakası olarak kullanılabilmektedir. Bu çalışmada fonksiyonel derecelendirilmiş sandviç kirişlerin titreşim } \\
\text { analizi yapılmıştır. Sandviç kirişin yüzey tabakaları fonksiyonel derecelendirilmiş, öz tabakası izotropik malzeme } \\
\text { olarak kabul edilmiştir. Sandviç kirişin yer değiştirme bileşenleri Euler-Bernoulli kiriş teorisi ile tanımlanmı, } \\
\text { farklı sınır koşulları için elde edilen kiriş denklemi transfer matris metodu ile çözülmüştür. Sandviç öz ve yüzey } \\
\text { tabakası kalınlık oranlarının ve hacimsel değişim üstelinin değişiminin doğal frekansın değişimi üzerindeki etkileri } \\
\text { incelenmiştir. Sandviç öz ve yüzey tabakası kalınlık oranlarının doğal frekans değeri üzerinde etkin olduğu ve } \\
\text { hacimsel değişim üstelindeki artışın tüm sınır koşulları için boyutsuz doğal frekans değerini düşürdüğü } \\
\text { görülmüştür. }\end{array}$} \\
\hline Geliş: 25 Aralık 2019 & \\
\hline Düzeltme: 9 Mart 2020 & \\
\hline Kabul: 10 Mart 2020 & \\
\hline Anahtar kelimeler: & \\
\hline $\begin{array}{l}\text { Fonksiyonel derecelendirilmiş, } \\
\text { sandviç, kiriş, titreşim }\end{array}$ & \\
\hline
\end{tabular}

Doi: $10.24012 /$ dumf. 664735

\begin{tabular}{|c|c|}
\hline ARTICLE INFO & ABSTRACT \\
\hline Article history: & \multirow{6}{*}{$\begin{array}{l}\text { Functionally graded materials are a special class of composite material that is designed for the working } \\
\text { environment not suitable for conventional material. Their material properties vary depending on a function } \\
\text { corresponding to the desired direction. Owing to the smooth gradient of material properties, functionally graded } \\
\text { materials eliminate the delamination problem of the laminated composites. Functionally graded materials can be } \\
\text { used as face sheets or core material in sandwich structures. In this study, the vibrational analysis of functionally } \\
\text { graded sandwich beams is presented. The face sheets of the sandwich beam are assumed functionally graded and } \\
\text { the core is assumed isotropic. The displacement fields of the sandwich beam are defined by Euler-Bernoulli's } \\
\text { beam theory. Beam equations for various boundary conditions are solved by the transfer matrix method. The } \\
\text { effects of core-face sheets thickness ratio and volume fraction on the natural frequency of the sandwich beam are } \\
\text { investigated. It is observed that the sandwich core and surface layer thickness ratios are effective on the natural } \\
\text { frequency values, and the increase in the volume fraction coefficient decreases the dimensionless natural frequency } \\
\text { values for all boundary conditions. }\end{array}$} \\
\hline Received: 24 December 2019 & \\
\hline Revised: 9 March 2020 & \\
\hline Accepted: 10 March 2020 & \\
\hline Keywords: & \\
\hline $\begin{array}{l}\text { Functionally graded, sandwich, } \\
\text { beam, vibration }\end{array}$ & \\
\hline
\end{tabular}

* Sorumlu yazar / Correspondence

Pınar Aydan DEMIRHAN

$\triangle$ pinard@trakya.edu.tr 


\section{Giriș}

Fonksiyonel derecelendirilmiş malzemeler iki malzemenin istenen doğrultuda bir fonksiyona bağlı olarak değiştiği özel bir kompozit malzeme sinifidir. Geleneksel malzemelerin uygun olmadığı çalışma koşullarında fonksiyonel derecelendirilmiş malzemelerin gösterdikleri performans dikkat çekmektedir. Katmanlı kompozit yapılarda ortaya çıkan tabaka ayrılması ve gerilme yığılmaları gibi problemler, fonksiyonel derecelendirilmiş malzemelerde malzeme özelliklerindeki yumuşak geçişler sayesinde ortadan kaldırılmıştır. 1980'lerde uzay uygulamaları için geliştirilen fonksiyonel derecelendirilmiş malzemeler günümüzde elektronik, biyomalzemeler, optik ve yapısal malzemeler olarak da kullanılmaktadır [1]. Fonksiyonel derecelendirilmiş malzemeler bu alanlarda tek başlarına kullanılabildiği gibi sıklıkla sandviç yapılarda öz veya yüzey tabakası olarak da kullanılmaktadır. Genellikle plak ve kiriş formunda kullanılan fonksiyonel derecelendirilmiş malzemelerle oluşturulmuş bu sandviç yapıların statik ve dinamik davranışlarının bilinmesi oldukça önemlidir [2].

Literatürde fonksiyonel derecelendirilmiş sandviç yapıların dinamik analizi ile ilgili çeşitli çalışmalar yer almaktadır. Li (2008) fonksiyonel derecelendirilmiş Euler-Bernoulli ve Timoshenko kirişlerin statik ve dinamik analizini kayma gerilmelerini hesaba katan bir yaklaşımla analiz etmiştir. Sina ve arkadaşları (2009) Birinci Mertebe Kayma deformasyon teorisini kullanarak fonksiyonel derecelendirilmiş kirişlerin titreşimi için analitik çözüm elde etmiştir. Vo ve arkadaşları (2014) ve Vo ve arkadaşları (2015) fonksiyonel derecelendirilmiş sandviç kirişlerin titreşim ve burkulma analizini sonlu elemanlar yöntemi ile yapmıştır. Gözenekli fonksiyonel derecelendirilmiş kirişlerin titreşim analizini Wattanasakulpong ve Ungbhakorn (2014) diferansiyel dönüşüm yöntemi ile yapmış, Wattanasakulpong ve Chaikittiratana (2015) Chebyshev sıralama metodu ile yapmıştır. Nguyen ve arkadaşları (2015) fonksiyonel derecelendirilmiş sandviç kirişlerin titreşim ve burkulma problemleri için yeni bir kayma deformasyon teorisi önermiştir. Nguyen ve arkadaşları (2016) fonksiyonel derecelendirilmiş sandviç kirişlerin titreşim ve burkulma problemleri için analitik çözüm elde etmiştir. Osofero ve arkadaşları (2016) fonksiyonel derecelendirilmiş sandviç kirişlerin titreşimi için yarı-üç boyutlu bir teori sunmuşlardır. Kitipornchai ve arkadaşları (2017) fonksiyonel derecelendirilmiş gözenekli kirişlerin burkulma ve titreşim analizini Ritz yöntemi ile yapmıştır. Demirhan (2016) fonksiyonel derecelendirilmiş sandviç kiriş ve plakların eğilme ve titreşim analizini dört değişkenli kayma deformasyon teorisi ile durum-uzay yöntemi kullanarak yapmıştır. Li ve arkadaşları (2017) eksenel fonksiyonel derecelendirilmiş kirişlerin eğilme, burkulma ve titreşim davranışlarını araştırmıştır. Al Rjoub ve Hamad (2017) gözenekli fonksiyonel derecelendirilmiş kirişlerin titreşim analizini transfer matris metoduyla yapmıştır. Bir dinamik analiz metoduna dayanan transfer matris yöntemi hareket denklemini elemanın iki ucundaki yer değiştirme ve kuvvet ilişkileriyle tanımlayan bir matrise indirgeyen bir yöntemdir. [13] Trinh ve arkadaşları (2016) fonksiyonel derecelendirilmiş sandviç kirişlerin titreşim analizini durum-uzay yaklaşımı ile yapmıştır. Fonksiyonel derecelendirilmiş sandviç plakların eğilme analizini Demirhan ve Taşkın (2017) durum-uzay yöntemi ile Demirhan ve Taşkın (2019a) Navier yaklaşımı ile sunmuştur. Demirhan ve Taşkın (2019b) gözenekli fonksiyonel derecelendirilmiş plakların eğilme ve titreşim analizini durum-uzay yöntemi ile sunmuştur. Kahya ve Turan (2018) yaptıkları çalışmada fonksiyonel derecelendirilmiş sandviç kirişlerin titreşim ve burkulma davranışlarını sonlu elemanlar yöntemi kullanarak analiz etmiştir. Şen ve Hüseyinoğlu (2018) yaptıkları çalışmada poliüretan takviye kalınlığının sandviç kirişin modal özelliklerine etkisini incelemiştir. Hüseyinoğlu ve Abut (2019) iki ucu ankastre U çerçeve yapının modal analizini sunan bir çalışma yapmıştır. Hüseyinoğlu ve arkadaşları (2019) ankastre mesnetli uniform ve uniform olmayan kesitli sandviç kirişlerin frekans 
analizini yapmıştır. Yapılan literatür araştırması sonucunda fonksiyonel derecelendirilmiş sandviç kirişlerin titreşim probleminin çözümünde transfer matris metodundan yararlanan bir çalışmaya rastlanmamıştır.

$\mathrm{Bu}$ çalışmada fonksiyonel derecelendirilmiş sandviç kirişlerin titreşim analizi sunulmuştur. Fonksiyonel derecelendirilmiş malzemenin etkin özelliklerinin değișimi karışımlar kuralı ile tanımlanmış, hacimsel değişim fonksiyonu olarak bir üstel fonksiyon seçilmiştir. Fonksiyonel derecelendirilmiș kirișin yer değiștirme bağıntıları Euler-Bernoulli kiriş teorisine göre tanımlanmıştır. Hareket denklemleri Hamilton prensibi kullanılarak elde edilmiştir. Farklı sınır koşulları için yönetici denklemlerin çözümünde transfer matris metodu kullanılmıştır. Elde edilen sonuçlar literatür ile karşılaştırılarak sunulmuştur.

\section{Materyal ve Yöntem}

h kalınlığında, L uzunluğunda yüzey tabakaları fonksiyonel derecelendirilmiş, seramik özlü bir sandviç kiriş dikkate alınmıştır (Şekil 1).

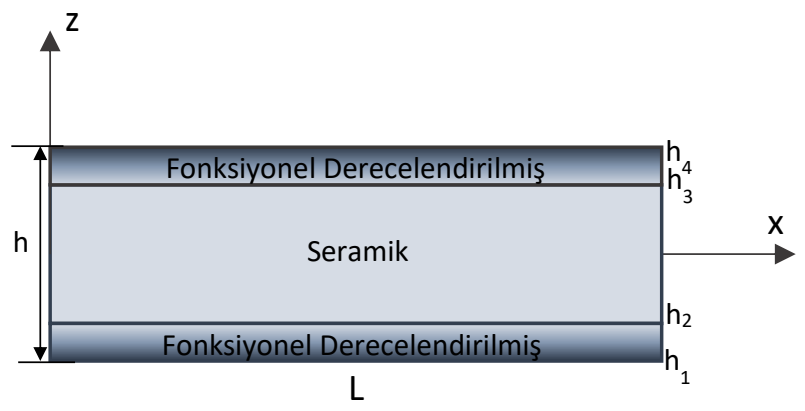

Şekil 1. Fonksiyonel derecelendirilmiş yüzeyli sandviç kiriş

Figure 1. Sandwich beam with functionally graded face sheets

Fonksiyonel derecelendirilmiş sandviç kirişin elastiklik modülünün kalınlıkla değişimi $\mathrm{E}(\mathrm{z})$, yoğunluk değişimi $\rho(z)$ fonksiyonu ile tanımlanmıştır.

$$
E(z)=E_{m}+\left(E_{s}-E_{m}\right) V(z)
$$$$
\rho(z)=\rho_{m}+\left(\rho_{s}-\rho_{m}\right) V(z)
$$

Burada $E_{m}$ ve $E_{s}$ sirasiyla metal ve seramik malzemenin elastiklik modülünü, $\rho_{m}$ ve $\rho_{s}$ sirasıyla metal ve seramik malzemenin yoğunluğunu temsil etmektedir.

$V(z)=\left\{\begin{array}{cc}\left(\frac{z-h_{1}}{h_{2}-h_{1}}\right)^{k} & h_{1}<z \leq h_{2} \\ 1 & h_{2}<z \leq h_{3} \\ \left(\frac{z-h_{4}}{h_{3}-h_{4}}\right)^{k} & h_{3}<z \leq h_{4}\end{array}\right.$

V(z) hacimsel değişim fonksiyonu Denklem 3 'teki gibi kabul edilmiştir. Burada $\mathrm{k}$ hacimsel değişim üstelini temsil etmekte, alt ve üst yüzey tabakaları p'nin sıfır değeri için seramik, k'nın sonsuz değeri için metal olmaktadır. k'nın diğer değerleri için alt ve üst yüzey tabakaları dış yüzeylerinde metalik özellik gösterirken, yüzeyden itibaren içe doğru ilerledikçe tabakanın seramik özelliği fonksiyona bağl1 olarak artmaktadir.

Euler-Bernoulli kiriş teorisine göre yer değiştirme bileşenleri Denklem 4-5'teki gibi tanımlanmıştır.
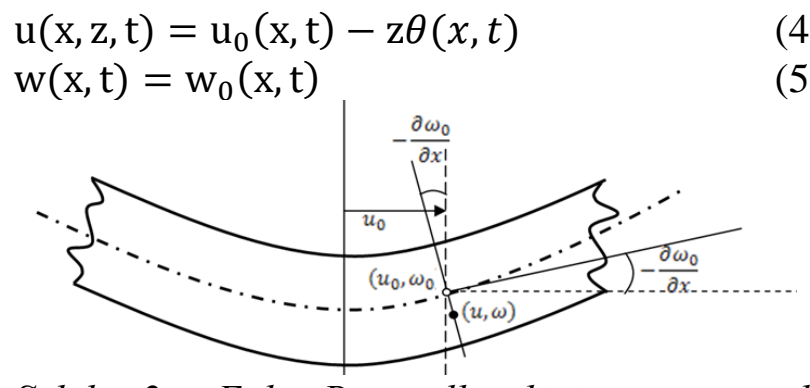

Şekil 2. Euler-Bernoulli kiriş teoreminde deformasyon [2]

Figure 2. Deformation of Euler-Bernoulli beam theory

Genleme yer değiştirme ilişkileri Denklem 67 'de verilmiştir.

$\varepsilon_{\mathrm{x}}=\frac{\partial \mathrm{u}}{\partial \mathrm{x}}-\mathrm{z} \frac{\partial \theta}{\partial \mathrm{x}}$

$\gamma_{\mathrm{xz}}=\frac{\partial \mathrm{w}}{\partial \mathrm{x}}+\theta$

Gerilme genleme ilişkileri Denklem 8-9'da verilmiştir.

$\sigma_{\mathrm{x}}=\mathrm{Q}_{11}(\mathrm{z}) \varepsilon_{\mathrm{x}}$

$\tau_{\mathrm{xz}}=\mathrm{Q}_{55}(\mathrm{z}) \gamma_{\mathrm{xz}}$ 
Rijitlik matrisi elemanları Denklem 10-11'de verilmiştir. Burada $\mathrm{Q}_{11}$ ve $\mathrm{Q}_{55}$ dönüştürülmüş rijitlik matrisi elemanlarıdır.

$\mathrm{Q}_{11}(\mathrm{z})=\frac{\mathrm{E}(\mathrm{z})}{\left(1-\mathrm{v}^{2}\right)}$

$\mathrm{Q}_{55}(\mathrm{z})=\frac{\mathrm{E}(\mathrm{z})}{2(1+\mathrm{v})}$

Hareket denklemlerinin elde edilmesinde Hamilton prensibinden yararlanılmıştır. $\delta \mathrm{U}, \delta \mathrm{V}$ ve $\delta \mathrm{K}$ sırasıyla genleme enerjisinin, dış kuvvet tarafından yapılan işin ve kinetik enerjinin varyasyonel ifadesidir.

$\int(\delta \mathrm{U}+\delta \mathrm{V}-\delta \mathrm{K}) \mathrm{dt}=0$

$\delta \mathrm{U}=\int_{0}^{\mathrm{L}} \int_{\mathrm{A}} \sigma_{\mathrm{x}} \delta \varepsilon_{\mathrm{x}} \mathrm{dAdx}$

$\delta \mathrm{V}=-\int_{0}^{\mathrm{L}} \mathrm{q} \delta \mathrm{wdx}$

$\delta \mathrm{K}=\int_{0}^{\mathrm{L}} \int_{\mathrm{A}} \rho(\mathrm{z})(\dot{\mathrm{u}} \delta \dot{\mathrm{u}}+\dot{\mathrm{w}} \delta \dot{\mathrm{w}}) \mathrm{dAdx}$

Denklem 13, 14 ve 15 Denklem 12'de yerine yazılır. İntegraller alındıktan sonra $\delta u$ ve $\delta w ' n i n$ katsayıları bir araya toplandığında Denklem 1617 elde edilir.

$\delta \mathrm{u}: \frac{\mathrm{dN}}{\mathrm{dx}}=0$

$\delta w: \frac{d^{2} M}{d x^{2}}=I \frac{d^{2} w}{{d t^{2}}^{2}}$

Eksenel kuvvet $(\mathrm{N})$ ve eğilme momenti (M) Denklem 18-19'da verilmiştir.

$\mathrm{N}=\int_{\mathrm{A}} \sigma_{\mathrm{x}} \mathrm{dA}$

$\mathrm{M}=\int_{\mathrm{A}} \mathrm{z} \sigma_{\mathrm{X}} \mathrm{dA}$

Atalet ifadesi Denklem 20'deki gibi tanımlanmıştır.

$\mathrm{I}=\int_{-\frac{\mathrm{h}}{2}}^{\frac{\mathrm{h}}{2}} \rho(\mathrm{z}) \mathrm{dz}$

Kuvvet ve moment bileşenleri Denklem 21'de verilmiştir.

$$
\left[\begin{array}{l}
N \\
M
\end{array}\right]=\left[\begin{array}{ll}
A & B \\
B & D
\end{array}\right]\left[\begin{array}{c}
\frac{d u}{d x} \\
-\frac{d^{2} w}{d x^{2}}
\end{array}\right]
$$

Rijitlik matrisi katsayıları Denklem 22'de tanımlanmıştır.

$\{A, B, D\}=\int_{-\frac{h}{2}}^{\frac{h}{2}}\left\{1, z, z^{2}\right\} Q_{11} d z$

Kuvvet ve moment bileşenleri Denklem 1617 'de yerlerine yazılarak sistemin hareket denklemleri aşağıdaki gibi elde edilir.

$A \frac{d^{2} u}{d x^{2}}-B \frac{d^{3} w}{d x^{3}}=0$

$\left(\mathrm{D}-\frac{B^{2}}{A}\right) \frac{\mathrm{d}^{4} \mathrm{w}}{\mathrm{dx}^{4}}=\mathrm{I} \frac{\mathrm{d}^{2} \mathrm{w}}{\mathrm{dt}^{2}}$

Fonksiyonel derecelendirilmiş sandviç kirişin serbest titreşiminde yer değiştirme bileşenleri Denklem 25-26'daki gibi kabul edilebilir:

$u(x, t) U e^{i \omega t}$

$w(x, t) W e^{i \omega t}$

Yer değiştirme bileşenleri hareket denklemlerinde yerlerine yazılarak zamana bağlı türevler alındığında denklem aşağıdaki şekli almıştır.

$\frac{\mathrm{d}^{4} \mathrm{w}}{\mathrm{dx}^{4}}-\lambda^{4} \mathrm{w}=0$

$\lambda^{4}=\left(\frac{\mathrm{AI} \omega^{2}}{A D-B^{2}}\right)$

Bu denklemin genel çözümü

$\mathrm{w}(\mathrm{x})=\mathrm{A}_{1} \sin \lambda x+\mathrm{A}_{2} \cos \lambda x+\mathrm{A}_{3} \sinh \lambda x+$

$\mathrm{A}_{4} \cosh \lambda x$

olarak bulunur. Buradan

$\mathrm{u}(\mathrm{x})=\frac{B}{A}\left(\mathrm{~A}_{1} \lambda \cos \lambda x-\mathrm{A}_{2} \lambda \sin \lambda x+\right.$

$\left.A_{3} \lambda \cosh \lambda x+A_{4} \lambda \sinh \lambda x\right)+A_{5} x+A_{6}$

elde edilir. Eksenel yer değiştirme U, dikine yer değiştirme $\mathrm{V}$, dönme $\theta$, eksenel kuvvet $\mathrm{N}$, moment $\mathrm{M}$ ve kesme kuvveti Q'nun uygunluk şartlarına göre sürekliliği göz önüne alınarak aşağıdaki gibi bir ilişki yazılabilir. 
$\left\{\begin{array}{c}U(l) \\ V(l) \\ \theta(l) \\ N(l) \\ M(l) \\ Q(l)\end{array}\right\}=[T]\left\{\begin{array}{c}U(0) \\ V(0) \\ \theta(0) \\ N(0) \\ M(0) \\ Q(0)\end{array}\right\}$
Burada $\mathrm{T}$ transfer matrisidir ve katsayıları Denklem 32'deki gibidir.

[T] $=$

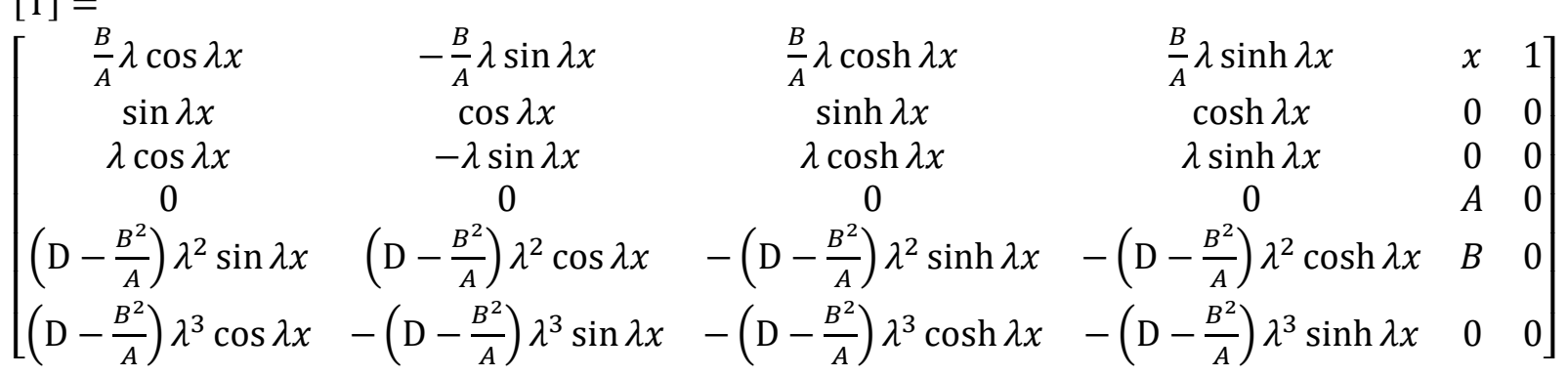

Fonksiyonel derecelendirilmiş sandviç kirişin sınır koşulları, $\mathrm{x}=0$ ve $\mathrm{L}$ değerlerini almak üzere

Basit (B) destek için,

$\mathrm{U}(x)=W(x)=M(x)=0$

Ankastre (A) destek için,

$\mathrm{U}(x)=W(x)=\theta(x)=0$

Serbest uç (S) için,

$\mathrm{N}(x)=M(x)=Q(x)=0$

Sınır koşulları uygunluk denkleminde yerine yazıldığında doğal frekansları içeren öz değer denklemleri elde edilir.

\section{Bulgular ve Değerlendirme}

$\mathrm{Bu}$ çalışmada fonksiyonel derecelendirilmiş yüzey tabakalı sandviç kirişlerin titreşim analizi transfer matris yöntemi kullanılarak elde edilmiştir. Sayısal sonuçların elde edilmesinde kullanılan malzeme özellikleri Tablo 1'de verilmiştir.
Tablo 1. Malzeme özellikleri

Table 1. Material properties

\begin{tabular}{lcc}
\hline Malzeme Özelliği & $\begin{array}{c}\text { Metal } \\
(\mathrm{Al})\end{array}$ & $\begin{array}{c}\text { Seramik } \\
\left(\mathrm{Al}_{2} \mathrm{O}_{3}\right)\end{array}$ \\
\hline Elastiklik Modülü, E(GPa) & 70 & 380 \\
Yoğunluk, $\rho\left(\mathrm{kg} / \mathrm{m}^{3}\right)$ & 2702 & 3960 \\
Poisson Oranı, $v$ & 0.3 & 0.3 \\
\hline
\end{tabular}

Literatürde yer alan çalışmalarla karşılaştırma yapabilmek için doğal frekans değerleri aşağıda verilen boyutsuzlaştırma ifadesi ile verilmiştir.

$\bar{\omega}=\omega \frac{L^{2}}{h} \sqrt{\frac{\rho_{m}}{E_{m}}}$

Sandviç kirişin yüzey tabakaları ve öz kalınlık oranları simetrik ve antisimetrik olarak Tablo 2'deki gibi tanımlanmıştır.

Tablo 2. Yüzey tabakası - öz tabakası kalınlık oranlart

Table 2. The face sheets-core thickness ratios

\begin{tabular}{ccccc}
\hline Kalınlik Oran1 & $\mathrm{h}_{1}$ & $\mathrm{~h}_{2}$ & $\mathrm{~h}_{3}$ & $\mathrm{~h}_{4}$ \\
\hline $1-1-1$ & $-\mathrm{h} / 2$ & $-\mathrm{h} / 6$ & $\mathrm{~h} / 6$ & $\mathrm{~h} / 2$ \\
$1-2-1$ & $-\mathrm{h} / 2$ & $-\mathrm{h} / 4$ & $\mathrm{~h} / 4$ & $\mathrm{~h} / 2$ \\
$2-1-2$ & $-\mathrm{h} / 2$ & $-\mathrm{h} / 10$ & $\mathrm{~h} / 10$ & $\mathrm{~h} / 2$ \\
$2-1-1$ & $-\mathrm{h} / 2$ & 0 & $\mathrm{~h} / 4$ & $\mathrm{~h} / 2$ \\
$2-2-1$ & $-\mathrm{h} / 2$ & $-\mathrm{h} / 10$ & $3 \mathrm{~h} / 4$ & $\mathrm{~h} / 2$ \\
$1-8-1$ & $-\mathrm{h} / 2$ & $-2 \mathrm{~h} / 5$ & $2 \mathrm{~h} / 5$ & $\mathrm{~h} / 2$ \\
\hline
\end{tabular}


Tablo3. Fonksiyonel derecelendirilmiş sandviç kirişlerin boyutsuz doğal frekans değerleri $(L / h=20)$

Table 3. The natural frequencies of functionally graded sandwich beams

\begin{tabular}{cclrrrr}
\hline $\begin{array}{c}\text { Kalınlık } \\
\text { oranları }\end{array}$ & $\mathrm{k}$ & \multicolumn{1}{c}{ Referans } & A-A & B-A & B-B & A-S \\
\hline $1-1-1$ & 0 & {$[14]$} & 12.4145 & 8.5560 & 5.4780 & 1.9525 \\
& & Bu çalışmada & 12.4311 & 8.5661 & 5.4835 & 1.9537 \\
\cline { 2 - 6 } & 1 & {$[14]$} & 9.1575 & 6.3110 & 4.0405 & 1.4405 \\
& & Bu çalışmada & 9.1684 & 6.3178 & 4.0442 & 1.4409 \\
\cline { 2 - 6 } & 10 & {$[14]$} & 6.7305 & 4.6385 & 2.9700 & 1.0585 \\
& & Bu çalışmada & 6.7382 & 4.6432 & 2.9723 & 1.0590 \\
\hline $1-2-1$ & 0 & {$[14]$} & 12.4145 & 8.5560 & 5.4780 & 1.9525 \\
& & Bu çalışmada & 12.4311 & 8.5661 & 5.4835 & 1.9537 \\
\cline { 2 - 6 } & 1 & {$[14]$} & 9.7410 & 6.7135 & 4.2980 & 1.5320 \\
& & Bu çalışmada & 9.7526 & 6.7204 & 4.3020 & 1.5327 \\
\cline { 2 - 6 } & 10 & {$[14]$} & 7.5815 & 5.2250 & 3.3455 & 1.1925 \\
& & Bu çalışmada & 7.5903 & 5.2304 & 3.3482 & 1.1929 \\
\hline $2-2-1$ & 0 & {$[14]$} & 12.4145 & 8.5560 & 5.4780 & 1.9525 \\
& & Bu çalışmada & 12.4311 & 8.5661 & 5.4835 & 1.9537 \\
\cline { 2 - 6 } & 1 & {$[14]$} & 9.4480 & 6.5195 & 4.1690 & 1.4860 \\
& & Bu çalışmada & 9.4594 & 6.5270 & 4.2035 & 1.4866 \\
\hline & 10 & {$[14]$} & 7.1750 & 4.9740 & 3.1660 & 1.1285 \\
& & Bu çalışmada & 7.1833 & 4.9792 & 3.2773 & 1.1289 \\
\hline
\end{tabular}

Tablo 3'te yüzey tabakası - öz kalınlık oranlarının farklı değerleri için fonksiyonel derecelendirilmiş sandviç kirişlerin boyutsuz doğal frekans değerleri farklı sınır koşulları ve hacimsel değişim üsteli k'nın 0,1 ve 10 değeri için verilmiştir.

Tablo 4'te fonksiyonel derecelendirilmiş sandviç kirişlerin farklı kalınlık oranı ve hacimsel değişim üsteli değerleri için boyutsuz doğal frekansları verilmiştir. Hacimsel değişim üsteli k değeri arttıkça sandviç kirişin yüzey tabakalarının metalik özelliği artmakta ve elastiklik modülü azalmaktadır. Bunun sonucu olarak tüm sınır koşulları için hacimsel değişim üsteli değeri arttıkça boyutsuz doğal frekans değerinin düştüğü görülmektedir. Her bir kalınlık oranı için en yüksek boyutsuz doğal frekans değeri iki tarafı ankastre mesnetli kirişte elde edilirken, en düşük boyutsuz frekans değerleri bir ucu ankastre diğer ucu serbest olan kirişte edilmiştir. Sandviç kirişin özü seramik malzeme olarak tanımlandığı için öz kalınlığı / yüzey tabakası kalınlığı oranı arttıkça doğal frekans değerleri yükselmektedir.

Tablo 5 'te öz - yüzey tabakası kalınlık oranlarına göre simetrik ve anti simetrik fonksiyonel derecelendirilmiş sandviç kirişlerin ilk üç titreşim modu için boyutsuz doğal frekans değerleri verilmiştir.

Şekil 3'te yüzey tabaka kalınlığının öz kalınlığına oranı 1-2-1 olan sandviç kirişin ilk üç doğal modu için boyutsuz doğal frekans değerlerinin hacimsel değişim üsteli $\mathrm{k}$ ile değişimi farklı sınır koşulları için verilmiştir. Her üç mod için en yüksek boyutsuz frekans değerleri iki ucu ankastre kirişte görülürken, en düşük frekans değerleri bir ucu ankastre diğer ucu serbest olan kirişte elde edilmiştir. Tüm sınır 
Tablo 4. Fonksiyonel derecelendirilmiş sandviç kirişlerin boyutsuz doğal frekans dĕgerleri Table 4. The natural frequencies of functionally graded sandwich beams $(L / h=10)$

\begin{tabular}{ccrccc}
\hline $\begin{array}{c}\text { Kalınlık } \\
\text { oranlar1 }\end{array}$ & $\mathrm{k}$ & $\mathrm{A}-\mathrm{A}$ & $\mathrm{B}-\mathrm{A}$ & $\mathrm{B}-\mathrm{B}$ & $\mathrm{A}-\mathrm{S}$ \\
\hline $1-2-1$ & 0 & 12.43048 & 8.56649 & 5.48339 & 1.95363 \\
& 1 & 9.75214 & 6.72070 & 4.30191 & 1.53269 \\
& 2 & 8.81214 & 6.07290 & 3.88725 & 1.38496 \\
& 5 & 7.93507 & 5.46847 & 3.50035 & 1.24711 \\
& 10 & 7.58994 & 5.23062 & 3.34811 & 1.19287 \\
\hline $2-1-2$ & 0 & 12.43048 & 8.56649 & 5.48339 & 1.95363 \\
& 1 & 8.81253 & 6.07317 & 3.88742 & 1.38502 \\
& 2 & 7.60421 & 5.24046 & 3.35440 & 1.19511 \\
& 5 & 6.65853 & 4.58874 & 2.93724 & 1.04649 \\
& 10 & 6.40351 & 4.41299 & 2.82474 & 1.00640 \\
\hline $1-8-1$ & 0 & 12.43048 & 8.56649 & 5.48339 & 1.95363 \\
& 1 & 11.20165 & 7.71964 & 4.94132 & 1.76050 \\
& 2 & 10.77851 & 7.42803 & 4.75466 & 1.69400 \\
& 5 & 10.36090 & 7.14023 & 4.57044 & 1.62837 \\
& 10 & 10.17705 & 7.01353 & 4.48935 & 1.59947 \\
\hline $2-2-1$ & 0 & 12.43048 & 8.56649 & 5.48339 & 1.95363 \\
& 1 & 9.45890 & 6.52659 & 4.20315 & 1.48660 \\
& 2 & 8.42091 & 5.81896 & 3.77379 & 1.32347 \\
& 5 & 7.50502 & 5.19715 & 3.40489 & 1.17952 \\
& 10 & 7.18296 & 4.97919 & 3.27701 & 1.12891 \\
\hline $2-1-1$ & 0 & 12.43048 & 8.56649 & 5.48339 & 1.95363 \\
& 1 & 9.04261 & 6.24189 & 4.02761 & 1.42118 \\
& 2 & 7.89871 & 5.46283 & 3.55745 & 1.24140 \\
& 5 & 6.99261 & 4.84773 & 3.19216 & 1.09899 \\
& 10 & 6.74019 & 4.67582 & 3.08772 & 1.05932 \\
\hline & & & & & \\
& & & & & \\
& & & & & \\
& 10 &
\end{tabular}

koșulları için, her üç mod için hacimsel değișim üsteli k'nın değeri arttıkça frekans değerlerinin düştüğü görülmektedir.

Şekil 4'te iki ucu ankastre mesnetlenmiş farklı öz-yüzey tabakası kalınlık oranlarına sahip sandviç kirişlerin boyutsuz doğal frekanslarının hacimsel değişim üsteli $\mathrm{k}$ ile değişimi verilmiştir. Hacimsel değişim üsteli k'nın tüm değerleri için öz kalınlığı/ yüzey tabakası kalınlığı oranı en düşük olan 2-1-2 tipi kirişin doğal frekans değerleri en düşükken, öz kalınlığının artmasıyla kirişin elastiklik modülü yükseldiğinden öz tabakasının oldukça kalın olduğu 1-8-1 tipi kirişte doğal frekans değerleri en büyüktür. Hacimsel değişim üsteli k'daki artış ile birlikte tüm kiriş tipleri için doğal frekans değerleri düşmektedir.

Şekil 5'te farklı sınır koşulları için uzunlukkalınlık oranı $\mathrm{L} / \mathrm{h}=20$ ve hacimsel değişim üsteli $\mathrm{k}=10$ değeri için 1-2-1 tipi sandviç kirişin ilk üç titreşim modu için mod şekilleri verilmiştir. 
Tablo 5. Fonksiyonel derecelendirilmişs sandviç kirişlerin ilk üç titreşim modu için boyutsuz doğal frekans değerleri

Table 5. First three natural frequencies of functionally graded sandwich beams

\begin{tabular}{cccrrrr}
\hline $\begin{array}{c}\text { Kalınlık } \\
\text { oranlar1 }\end{array}$ & $\mathrm{k}$ & Mod & \multicolumn{1}{c}{ A-A } & \multicolumn{1}{c}{ B-A } & \multicolumn{1}{c}{ B-B } & \multicolumn{1}{c}{ A-S } \\
\hline $1-2-1$ & 0 & 1 & 12.4311 & 8.5661 & 5.4835 & 1.9537 \\
& & 2 & 34.2714 & 27.7708 & 21.9393 & 12.2519 \\
& & 3 & 67.1764 & 60.0916 & 49.3631 & 34.2886 \\
\cline { 2 - 7 } & 1 & 1 & 9.7526 & 6.7204 & 4.3020 & 1.5327 \\
& & 2 & 26.8871 & 21.7872 & 17.2121 & 9.61203 \\
& & 3 & 52.7022 & 47.1439 & 38.7270 & 26.9006 \\
\cline { 2 - 7 } & 10 & 1 & 7.5903 & 5.2304 & 3.3482 & 1.1929 \\
& & 2 & 20.9258 & 16.9566 & 13.3959 & 7.4809 \\
$2-2-1$ & 0 & 1 & 12.4145 & 8.5661 & 5.4780 & 1.9525 \\
& & 2 & 34.2714 & 27.7708 & 21.9393 & 12.2519 \\
& & 3 & 67.1754 & 57.9390 & 49.3631 & 34.2886 \\
\cline { 2 - 6 } & 1 & 1 & 9.4480 & 6.7204 & 4.1690 & 1.4860 \\
& & 2 & 39.2701 & 21.1320 & 16.6946 & 9.3230 \\
& & 3 & 51.1175 & 44.0883 & 37.5944 & 26.0917 \\
\cline { 2 - 6 } & 10 & 1 & 7.1750 & 5.2304 & 3.2773 & 1.1289 \\
& & 2 & 19.8037 & 16.0746 & 12.6776 & 7.0798 \\
& & 3 & 38.8180 & 33.5063 & 28.6335 & 19.8137 \\
\hline
\end{tabular}

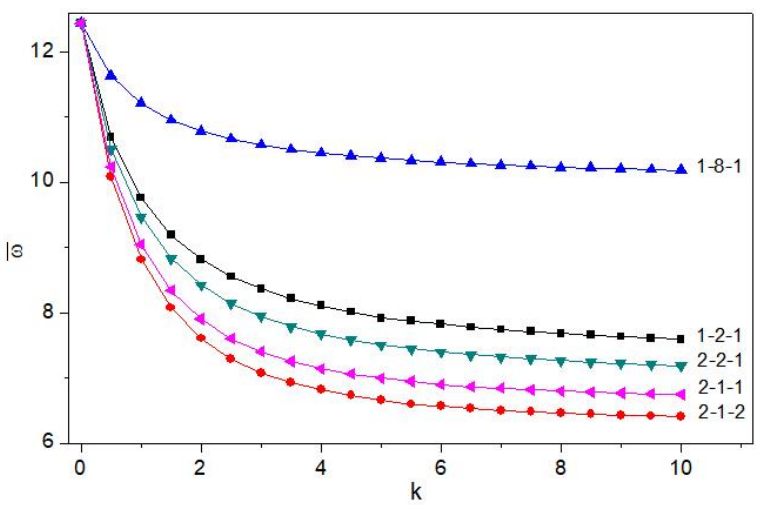

Şekil 3. Farklı kalınlık oranlarına sahip iki ucu ankastre sandviç kirişlerin doğal frekanslarının hacimsel değişim üsteli ile değişimi

Figure 3. Variations of the frequencies of clamped-clamped sandwich beams with different thickness ratios corresponding volume fraction coefficient 

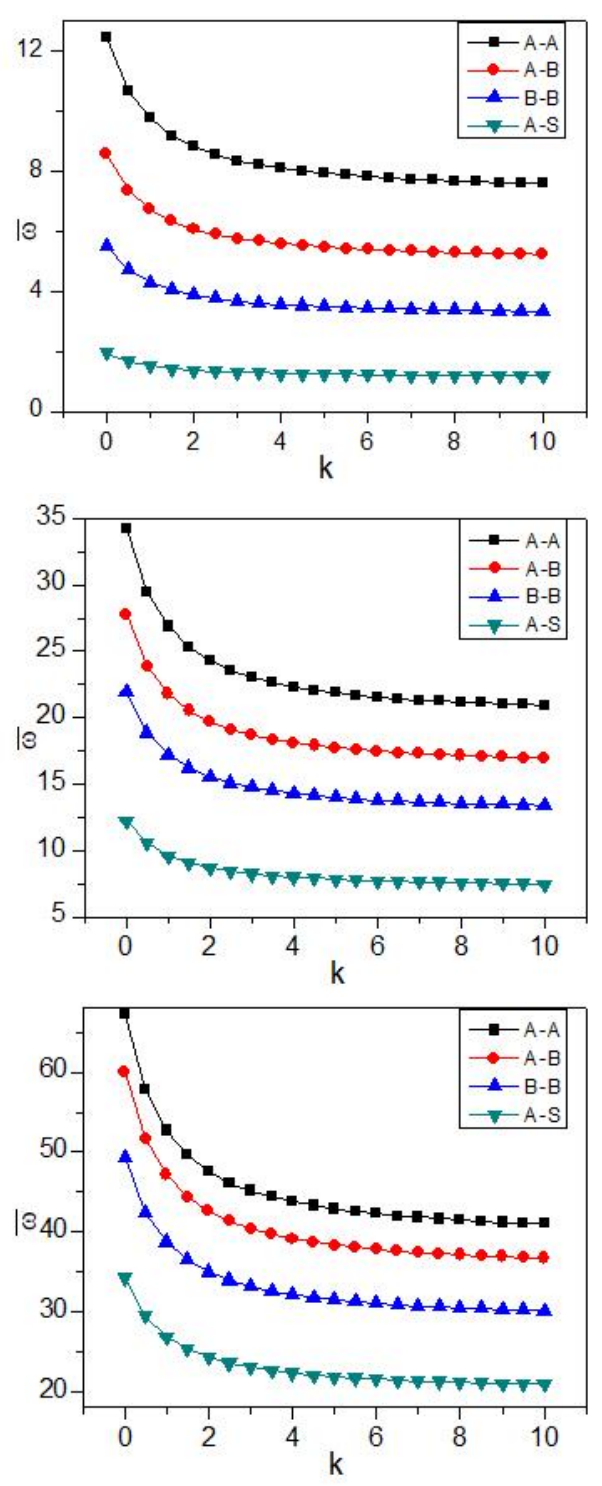

Şekil 4. 1-2-1 oranll sandviç kirişin ilk üç titreşim modu için doğal frekanslarının hacimsel değissim üsteli ile değisşimi

Figure 3. Variation of first three natural frequencies of 1-2-1 type sandwich beams corresponding volume fraction coefficient
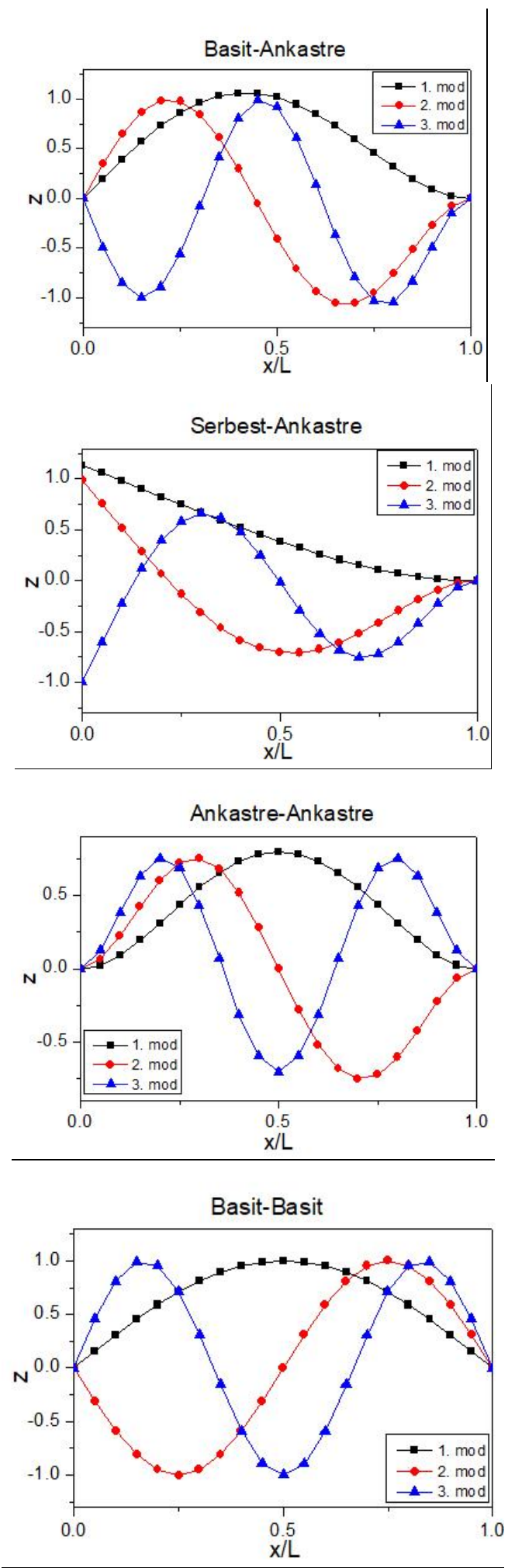

Şekil 5. 1-2-1 tipi sandviç kirişin farklı sınır koşulları için ilk üç titreşim modu

Figure 5. First three natural frequencies of 1-21 type sandwich beams for various boundary conditions 


\section{Sonuçlar}

$\mathrm{Bu}$ çalışmada fonksiyonel derecelendirilmiş sandviç kirişlerin titreşim analizi Euler-Bernoulli kiriş teorisi kullanılarak yapılmıştır. Üstel bir fonksiyona bağlı olarak değişen malzeme etkin özellikleri karışımlar kuralı ile tanımlanmıştır. Hareket denklemlerinin elde edilmesinde sanal iş ilkesinden yararlanılmış ve farklı sınır koşulları için elde edilen öz değer problemi transfer matris metodu ile çözülmüştür. Sonuçlar literatür ile karşılaştırılarak sunulmuş̧ur. Farklı tipte sandviç kirişler incelendiğinde öz kalınlığ1/ yüzey tabakası kalınlığı oranı en düşük kirişin doğal frekans değerlerinin en düşük olduğu bulunurken, öz kalınlığının artmasıyla kirişin elastiklik modülü yükseldiğinden öz tabakası kalınlığı arttıkça doğal frekans değerlerinin arttığ 1 görülmüştür. Hacimsel değişim üsteli k' nın artması ile yüzey tabakalarının metalik özellikleri artmakta ve bundan dolayı elastik modülleri düşmektedir. $\mathrm{Bu}$ nedenle tüm kiriş tipleri için hacimsel değişim üstelinin artması ile doğal frekans değerleri azalmaktadır.

\section{Kaynaklar}

[1] T.K. Nguyen and B.D. Nguyen, "New higher-order shear deformation theory for static, buckling and free vibration analysis of functionally graded sandwich beams,", Journal of Sandwich Structures and Materials, vol. 17, no 6, pp. 613-63, 2015. https://doi.org/10.1177/1099636215589237

[2] Pinar Aydan Demirhan, "Fonksiyonel Derecelendirilmiş Sandviç Kiriş Ve Plakların Dört Değişkenli Kayma Deformasyon Teorisi İle Eğilme Ve Titreşim Analizi”, Doktora Tezi, Trakya Üniversitesi Fen Bilimleri Enstitüsü, Edirne, 2016.

[3] X.F. Li, "A unified approach for analyzing static and dynamic behaviors of functionally graded Timoshenko and Euler-Bernoulli beams,", Journal of Sound and Vibration, vol. 318, pp. 1210-1229, 2008. https://doi.org/10.1016/j.jsv.2008.04.056

[4] S.A. Sina, H.M. Navazi and H. Haddadpour, "An analytical method for free vibration analysis of functionally graded beams,", Materials and Design, vol. 30, pp. 741-747, 2009. https://doi.org/10.1016/j.matdes.2008.05.015

[5] T.P. Vo, H.T. Thai, T.K. Nguyen, A. Maheri and J. Lee, "Finite element model for vibration and buckling of functionally graded sandwich beams based on a refined shear deformation theory,", Engineering Structures, vol. 64, pp. 12-22, 2014. http://dx.doi.org/10.1016/j.engstruct.2014.01.029
[6] T.P. Vo, H.T. Thai, T.K. Nguyen, F. Inam and J. Lee, "A quasi-3D theory for vibration and buckling of functionally graded sandwich beams,", Composite Structures, vol. 119, pp. 1-12, 2015. http://dx.doi.org/10.1016/j.compstruct.2014.08.006

[7] N. Wattanasakulpong and V. Ungbhakorn, "Linear and nonlinear vibration analysis of elastically restrained ends FGM beams with porosities,", Aerospace Science and Technology, vol. 32, pp. 111-120, 2014. http://dx.doi.org/10.1016/j.ast.2013.12.002

[8] N. Wattanasakulpong and A. Chaikittiratana, "Flexural vibration of imperfect functionally graded beams based on Timoshenko beam theory: Chebyshev collocation method,", Meccanica, vol. 50, pp.1331-1342,

2015. http://dx.doi.org/10.1007/s11012-014-0094-8

[9] T.K. Nguyen, T.T.P. Nguyen, T.P. Vo and H.T. Thai, "Vibration and buckling analysis of functionally graded sandwich beams by a new higher-order shear deformation theory,", Composites Part B, vol. 76, pp. 273-285,

2015. http://dx.doi.org/10.1016/j.compositesb.2015.02.032

[10] T.K. Nguyen, T.P. Vo, B.D. Nguyen and J. Lee, “An analytical solution for buckling and vibration analysis of functionally graded sandwich beams using a quasi3D shear deformation theory,", Composite Structures, vol. 156, 238-252, 2016. http://dx.doi.org/10.1016/j.compstruct.2015.11.074

[11] A.I. Osofero, T.P. Vo, T.K. Nguyen and J. Lee, "Analytical solution for vibration and buckling of functionally graded sandwich beams using various quasi-3D theories,", Journal of Sandwich Structures and Materials, Vol. 18, no 1, pp. 3-29, 2018. http://dx.doi.org/10.1177/1099636215582217

[12] S. Kitipornchai, D. Chen and J. Yang, "Free vibration and elastic buckling of functionally graded porous beams reinforced by graphene platelets,", Materials and Design vol. 116, pp. 656-665, 2017. http://dx.doi.org/10.1016/j.matdes.2016.12.061

[13] M. Boiangiu, V. Ceausu, C.D. Untaroiu, “A transfer matrix method for free vibration analysis of EulerBernoulli beams with variable cross section,", Journal of Vibration and Control, vol.22, no.11, pp. 25912602,

2014. https://doi.org/10.1177/1077546314550699

[14] L.C. Trinh, T.P. Vo, A.I. Osofero and J. Lee, "Fundamental frequency analysis of functionally graded sandwich beams based on the state space approach,", Composite Structures, vol. 156, pp. 263 275,

2016. http://dx.doi.org/10.1016/j.compstruct.2015.11.010

[15] P.A. Demirhan and V. Taskin, "Levy solution for bending analysis of functionally graded sandwich plates based on four variable plate theory,", 
Composite Structures, vol. 177, pp. 80-95, 2017. http://dx.doi.org/10.1016/j.compstruct.2017.06.048

[16] P.A. Demirhan and V. Taskin, "Static analysis of simply supported functionally graded sandwich plates by using four variable plate theory,", Teknik Dergi, vol. 30, no 2, pp. 8987-9007, 2019a. https://dx.doi.org/10.18400/tekderg.396672

[17] P.A. Demirhan and V. Taskin, "Bending and free vibration analysis of Levy-type porous functionally graded plate using state space approach,", Composites Part B, vol. 160, pp. 661-676, 2019b. https://doi.org/10.1016/j.compositesb.2018.12.020

[18] X. Li, L. Li, Y. Hu, Z. Ding and W. Deng, "Bending, buckling and vibration of axially functionally graded beams based on nonlocal strain gradient theory,", Composite Structures, vol. 165, pp. 250-265, 2017. http://dx.doi.org/10.1016/j.compstruct.2017.01.032

[19] Y.S. Al Rjoub and A.G. Hamad, "Free vibration of functionally euler-bernoulli and timoshenko graded porous beams using the transfer matrix method,", KSCE Journal of Civil Engineering, vol. 21, no 3, pp.792-806, 2017. https://doi.org/10.1007/s12205016-0149-6

[20] V. Kahya and M. Turan, "Vibration and stability analysis of functionally graded sandwich beams by a multi-layer finite element,", Composites Part B, vol. 146, $\quad$ pp.198-212, 2018. https://doi.org/10.1016/j.compositesb.2018.04.011

[21] M. Şen, M. Hüseyinoğlu, "Investigation of the Effects of Polyurethane Foam Reinforcement Thickness on Modal Properties of Sandwich Beams", Muş Alparslan Üniversitesi Fen Bilimleri Dergisi,vol. 6, no.1, pp. 511-517, 2018. https://dergipark.org.tr/tr/pub/msufbd/issue/37908/4 38101

[22] M. Hüseyinoglu, T. Abut, "İki Ucu Ankastre U Çerçeve Yapının Modal Analizi”, Muş Alparslan Üniversitesi Fen Bilimleri Dergisi, vol. 7, pp.657665, 2019. https://doi.org/10.18586/msufbd.637678.

[23] M. Hüseyinoğlu, M. Şen, O. Yiğid, O. Çakar, "Dynamic Analysis of Uniform and Non-Uniform Cross-Section Cantilever Sandwich Beams", European Journal of Technique (EJT), vol. 9, no.2, pp. 286-297, 2019 https://doi.org/10.36222/ejt.632784 